\title{
Review: structure of amyloid fibril in diseases
}

\author{
Arezou Ghahghaei ${ }^{1^{*}}$, Nasim Faridi ${ }^{1}$ \\ ${ }^{1}$ Department of Biology, Faculty of Science, University of Sistan and Baluchestan, Zahedan, Iran. \\ Email: Arezou@chem.usb.ac.ir
}

Received 8 May 2009; revised 13 July 2009; accepted 21 July 2009.

\begin{abstract}
Tissue deposition of normally soluble proteins, or their fragments, as insoluble amyloid fibrils causes both acquired and hereditary systemic amyloidoses, which is usually fatal. Amyloid is associated with serious diseases such as Alzheimer's disease, type 2 diabetes, Parkinson's Disease, Huntington's Disease, cancer and the transmissible spongiform encephalopathies. Information concerning the structure and mechanism of formation of fibrils in these diseases is critical for understanding the process of pathology of the amyloidoses and to the development of more effective therapeutic agents that target the underlying disease mechanisms. Structural models have been made using information from a wide variety of techniques, including electron microscopy, X-ray diffraction, solid state NMR, and Congo red and CD spectroscopy. Although each type of amyloidosis is characterised by a specific amyloid fibril protein, the deposits share pathognomonic histochemical properties and the structural morphology of all amyloid fibrils is very similar. In fact, the structural similarity that defines amyloid fibres exists principally at the level of $\beta$-sheet folding of the polypeptides within the protofilament, while the different types vary in the supramolecular assembly of their protofilaments.
\end{abstract}

Keywords: Amyloid; Protofilaments; Aggregation; Neurodegenerative

\section{INTRODUCTION}

Amyloid fibril formation arises from the slow aggregation of intermediately folded peptide or protein molecules. During this process the protein goes from its native soluble form to insoluble fibril, which is highly $\beta$ sheet in character $[1,2,3,4]$. The aggregation of the amyloid $\beta$ peptide has been examined in various solvents and conditions and this has led to a model by which a con- formational switching occurs from an $\alpha$-helix or random coil to a $\beta$-sheet structure early on the amyloid-forming pathway [5], prior to a nucleation-dependent process leading to the elongation of the fibril. Along this pathway, small oligomeric intermediates and short fibrillar structures (protofibrils) have been observed. In crosssection, the fibril appears to be composed of several subfibrils or protofilaments. Each of these protofilaments is rich in stacked $\beta$-sheet structures in which hydrogen bonded $\beta$-strands run perpendicular to the fibril's axis, and the backbone hydrogen bonds are parallel to it [6].

The basic process of amyloid formation is known to involve the construction of fibrils from individual polypeptide monomer units held together by noncovalent interactions generated by the formation of intermolecular $\beta$-sheets or the correct stacking of intramolecular $\beta$-sheet structures [7]. Small polypeptide fragments (as small as five or six residues long) are able to form amyloid fibrils from fully denatured conformations, larger sequences, typically between 80 and 150 residues, appear to require the population of more compact or partially folded states to form amyloids [7]. In a number of systems it has been demonstrated that amyloid fibril formation by proteins in vitro is preceded by the formation of metastable, nonfibrillar forms often referred to as protofibrils. These species often have the appearance of spherical beads $2-5 \mathrm{~nm}$ in diameter, beaded chains, where the individual beads again have a diameter of $2-5 \mathrm{~nm}$, or annular structures, formed apparently by the circularisation of the beaded chains.

Figure 1 suggests that the various fates awaiting a polypeptide chain, once it has been synthesized in the cell, will depend on the kinetics and thermodynamics of the various equilibria between various possible states $[5,8]$. In its monomeric state, the protein is believed to fold from its highly disordered unfolded state (3) through a partially structured intermediate state (2) to a globular native state $(1)[8,9]$. The unfolded and partially folded states can form aggregated species that are frequently disordered. Highly ordered amyloid fibrils can form through a mechanism of nucleation and elongation $[8,9,10]$ showed that the $\beta$-domain is the destabilized region of the human lysozyme. This implies that the aggregation process may be initiated by intermolecular rather than intramolecular association $[8,10,11]$. 


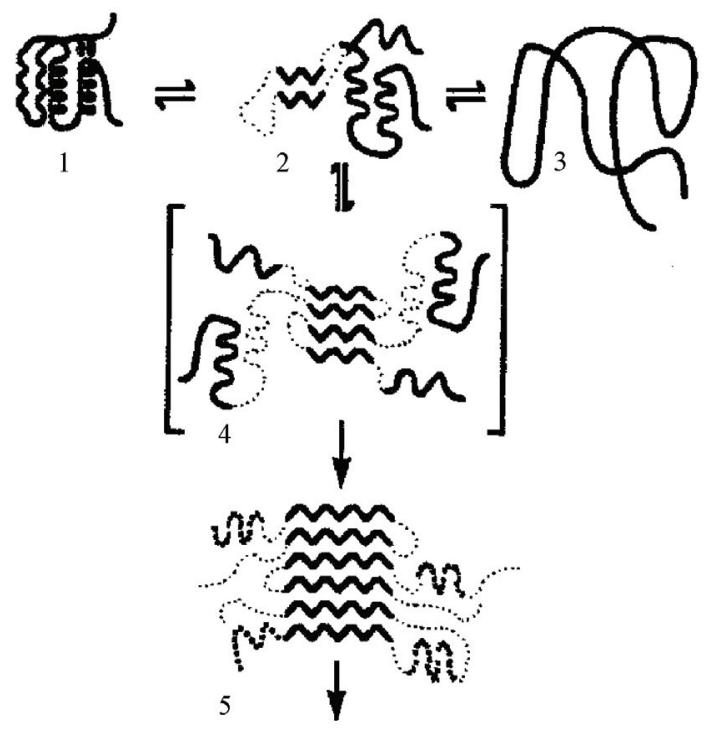

Figure 1. A proposed mechanism for lysozyme amyloid fibril formation [8]. An intermediate structural state form of the protein (2) aggregates through the $\beta$ domain (4) to commence fibril formation. This intermediate (4) shows a pattern for the development of the fibril.

Negative-stain electron microscopy (EM) showed that the amyloid fibrils associated with the various diseases mostly appear straight, and unbranched, and are 30-120 $\AA$ in diameter. They consist of two or more filamentous subunits, which twist around each other with $11.5 \mathrm{~nm}$, $24 \beta$-strand periodicity resulting in a protofilament diameter of 5-6 nm. The amyloid fibril, shown in Figure 2 , is about $25-35 \AA$ wide and consists of two or three subunit strands helically arranged with a 35-50 $\AA$ diameter repeat $[12,13,14,15,16,17]$.

$\mathrm{X}$-ray fibre diffraction showed that all types of fibrils have a common core structure $[18,19,20,21]$. They consist of a helical array of $\beta$-sheets along the length of the fibre. This indicates that the polypeptide chain in fibres are hydrogen-bonded together along their entire length which increases their stability $[18,19,20,21]$. Cross $\beta$ sheets consist of two dominant reflections: a sharp and intense meridional reflection at $4.8 \AA$, which corresponds to the average distance between the hydrogenbonded $\beta$-strands that comprise $\beta$-sheets and a strong and more diffuse reflection on the equator between 9-11 $\AA$ arising from the distance between stacked $\beta$-sheets, $[18,19,20,21]$. The X-ray diffraction pattern of PI3-SH3 fibril is shown in Figure 3 [21]. The fibril contains two reflections: the main reflection, which is intense, occurs at $4.71 \AA$ while the weaker reflections appear at 9.42.

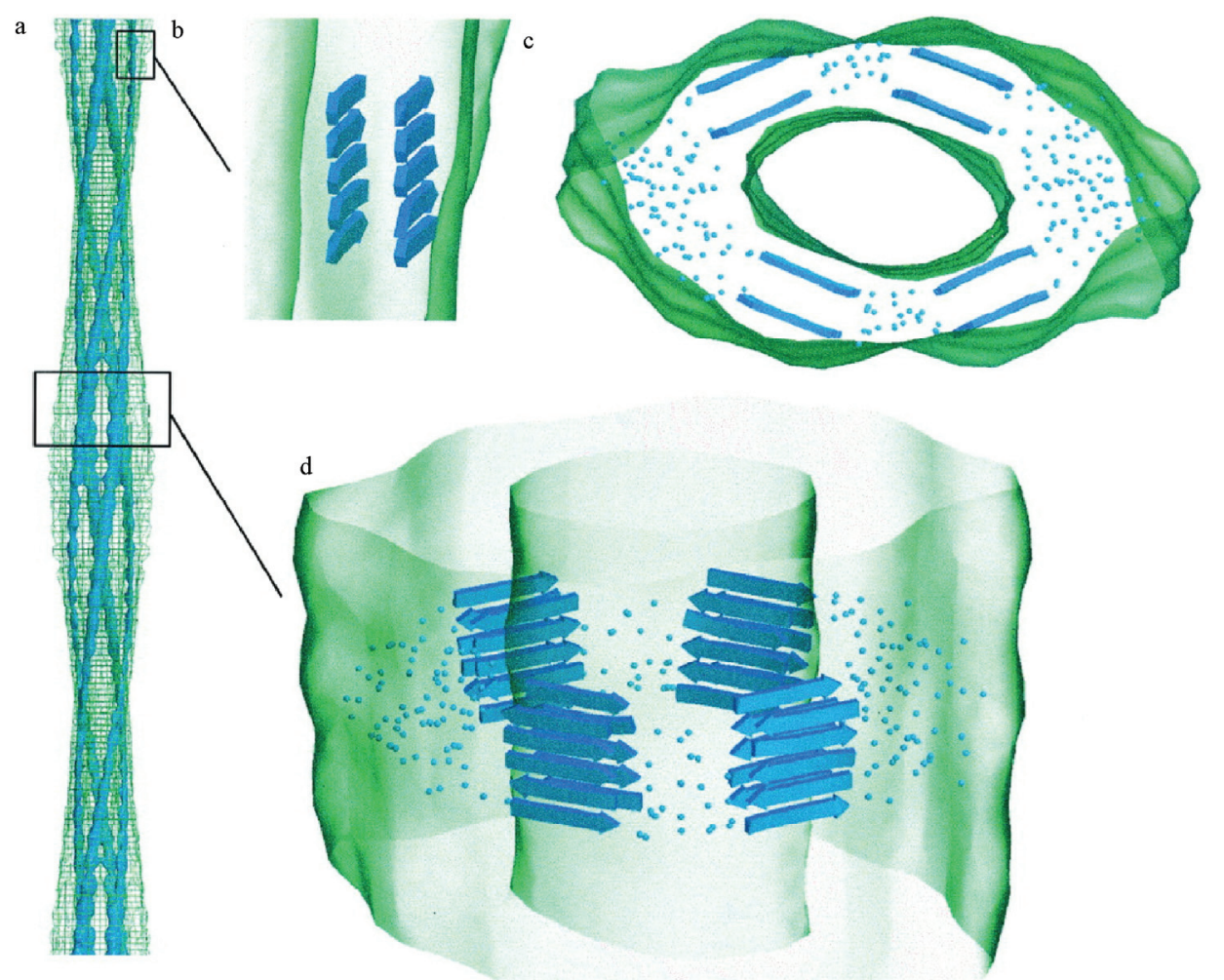

Figure 2. Modeling of an amyloid fibril structure. (a) Overview of the fibril structure showing protofilaments extended in regular helical twists along the length of the fibre (b) Side view of inter-sheet spacing between subprotofilaments of 9-11 § perpendicular to the axis (c) Cross-section of amyloid fibril (d) Slightly tilted side view of the fibril showing inter-strand spacing of $4.7 \AA$ along the fibre axis [16]. 


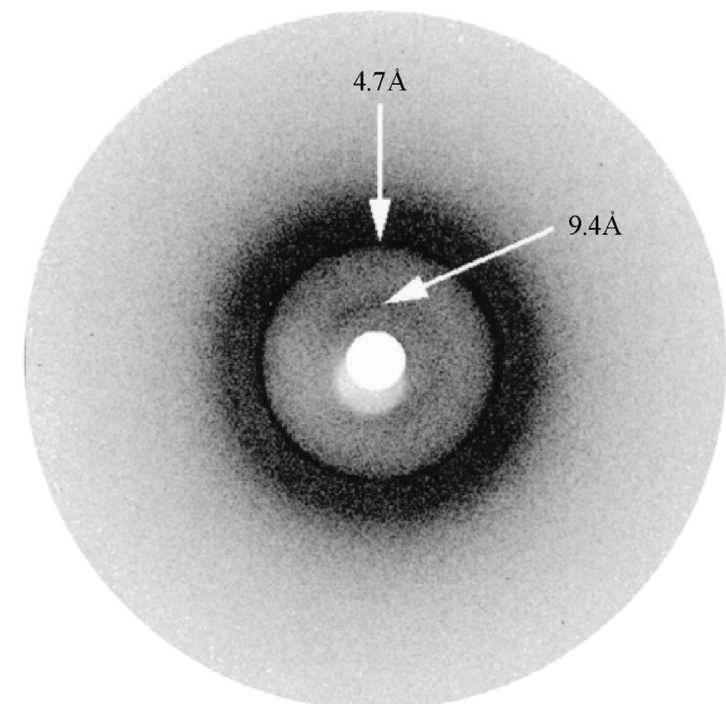

Figure 3. X-ray diffraction pattern of PI3-SH3 fibrils. The meridional (interstrand spacing) and equatorial (intersheet spacing) reflections are indicated at $4.7 \AA$ and $9.4 \AA$, respectively [21].

In some systems, small amounts of preformed amyloid fibrils, added to the sample to act as seeds, induce the formation of amyloid fibrils more readily if protofibrils are present in the sample rather than nonaggregated or smaller oligomeric species. This observation suggests that, in these cases at least, fibrils can form preferentially from the assembly of protofibrils. Evidence exists, however, that some oligomeric aggregates assembling into chains and rings with "bead-on-string" morphology may be off-pathway species that are not amyloid-competent [22].

The soluble precursors of amyloid deposits do not share any sequence homology or common fold. However, amyloid aggregates have common structural features: 1) they show the same optical behavior (such as birefringence) on binding certain dye molecules like Congo red; 2) they present very similar morphologies (long, unbranched and often twisted fibrillar structures a few nanometers in diameter); and 3) they display the characteristic cross- $\beta$ X-ray diffraction pattern which indicates that the "core" structure is composed of $\beta$-sheets running perpendicular to the fibril axis. [5,23].

\section{AMYLOIDOSIS DISEASES}

Amyloid formation is associated with a number of diseases e.g. Alzheimer's, Parkinson's, Huntington's, Creutzfeldt-Jakob, Spongiform and other neurodegenerative diseases in which the formation of $\beta$-sheet aggregates known as amyloid plaques that, among other features, are extremely resistant to protease action, an indication of close packed clusters. All these diseases are primarily associated with old age [3, $24,25]$. It is a general observation that solubility and protease resistance depend on actual secondary structure. A helical and or random coil content has been shown to be coincident with high solubility and protease susceptibility whereas a $\beta$-sheet content has been shown to determine poor solubility and resistance to proteolysis [26,27]. The clinical classification of amyloidosis includes primary (de novo), secondary (a complication of a previously existing disorder), familial, and isolated types $[28,29]$. Each disease is characterized by a particular protein or polypeptide that aggregates in an ordered manner to form insoluble amyloid fibrils [30]. These amyloid fibrils are deposited in the tissues, where they are associated with the pathology of the disease [31].

There are relatively few examples of nonpathological functions. Given that many proteins have the ability to form amyloids. Among the few known functions are the amyloid curli, adhesive appendages of gram-negative bacteria, and yeast regulatory amyloids that may mediate epigenetic diversification. Recently, a natural amyloid has been found to accelerate melanin assembly in melanocytes. Amyloids have been proposed to have a role in the establishment of memory, as well. The discovery of new functions for amyloids would greatly increase our knowledge of their roles in the normal functioning of cells [32]. The role of amyloid $\beta$-peptide in the pathogenesis of neurodegenerative disorders is not completely elucidated, but its toxic effect is not necessarily correlated with senile plaque deposition, since it has been shown that the neurotoxic effect of amyloid $\beta$ peptide is independent of plaque formation in transgenic mouse models. It has been suggested that neurotoxic effects can be induced by diffusible amyloid $\beta$-peptide oligomers or by intraneuronal accumulation of amyloid $\beta$-peptide [33].

The function of the majority of proteins is attributable to its unique three dimensional structure [34]. Failure to fold to into its correct structure limits of abrogates the protein's ability to perform the biological roles for which it was produced [35]. Not only does the aggregation of folding intermediates strips the cell of an important resource, the presence of the aggregate themselves can have dire consequence and results in a wide range of disease such as described in the Table 1.

Conformational diseases such as those in Table 1 are associated with proteins that do not attain or maintain their native structure resulting in aggregation and insolubilization [36,37]. The insoluble deposits in this disease form either plaques or fibrillar tangles within tissues and their accumulation ultimately result in cell damage or death $[35,38]$. 
Table 1. Representative human disease associated with defective protein folding [113,114,115].

\begin{tabular}{lcc}
\hline \multicolumn{1}{c}{ Disease } & Protein & Phenotype \\
\hline Alzheimer's disease & $\beta$-Amyloid & Aggregation \\
Tay-Sachs disease & $\beta$-Hexasominidase & Improper trafficking \\
Cancer & PS3 & Misfolding/improper trafficking \\
Spongiform & Prion Protein & Aggregation \\
Creutz feldt-jakob diseases & Prion protein & Aggregation \\
Maifan syndrom & Fibrillin & Misfolding \\
Parkinson diseases & $\alpha$-Synuclein & Aggregation \\
Gaucher's disease & $\beta$-Glucosidase & Improper trafficking \\
Scurvy & Collagen & Misfolding \\
Huntington's diseases & Huntington & Aggregation \\
Familial amyloiosis & Transthyretin & Aggregation \\
\hline
\end{tabular}

\section{THE ALZHEIMER'S DISEASE}

Alzheimer's disease (AD) is one of the most common neurodegenerative disorders associated with aging, and is characterized by fibrillar deposits of amyloid $\beta(\mathrm{A} \beta)$ peptides in the brain parenchyma and cortical blood vessels [5,37,39]. Patients in Alzheimer's disease often have psychiatric manifestations of disease, such as psychosis (e.g., delusions and hallucinations) and disruptive behaviors (e.g., psychomotor agitation and physical aggression), especially in the later stages of the disease (1). One of the characteristics of brains afflicted with $\mathrm{AD}$ is the presence of extracellular structural elements referred to as amyloid plaques. Plaques are, in part, composed of masses of filaments, which are in turn composed of the insoluble form of the $A \beta$ peptide $[5,39,40]$. These $A \beta$ aggregates may cause neuronal injury directly by acting on synapses, or indirectly by activating microglia and astrocytes and therefore pharmacological interventions have been developed to target the sequential events originating from $A \beta$ synthesis $[40,41]$. Usually neuritic plaques composed of amyloid $\beta$-protein $(A \beta)$ are an early and invariant neuropathological feature of Alzheimer's disease (AD), [41]. Genetic and neuropatho logical studies suggest that the processing of amyloid precursor protein (APP) to yield amyloid $\beta$-protein (A $\beta)$, and its subsequent aggregation, play important roles in the pathogenesis of Alzheimer's disease (AD) as the numbers of $A \beta$ plaques and $A \beta$ burden increased over time in the brain with $\mathrm{AD}$ and $\mathrm{A} \beta$ deposition precedes clinical symptom of AD. The other pathological feature of this disease is intraneural neurofibrillary tangles [ $[42$, $43,44]$.

The $\mathrm{A} \beta$ family of peptides is derived by the enzymatic breakdown of the amyloid precursor protein (APP), a 563-770 residue membrane protein expressed in neuronal and non-neuronal tissue [45]. Patients with Down syndrome develop $\mathrm{AD}$ because of an extra copy of the amyloid precursor protein $(A P P)$ gene on chromosome 21 [46]. Amyloid precursor protein (APP) is a ubiquitous membrane glycoprotein encoded by a single gene on chromosome 21 and formed as a cleavage byproduct by three proteases, $\beta-, \gamma$ - nd $\alpha$-secretase [47]. It's cleavege via the $\alpha$-secretase or the $\beta$-secretase pathway, often referred to as the amyloidogenic pathway. When APP is cleaved by $\alpha$-secretase, it produces a large aminoterminal fragment $\mathrm{APP} \alpha$ destined for secretion and a smaller carboxyl-terminal fragment. Further processing of the carboxyl-terminal fragment by $\gamma$-secretase produces a 22- to 24-residue fragment termed P3, which may or may not be amyloidogenic. Alternatively, when APP is cleaved by $\beta$-secretase it produces a soluble amino-terminal fragment, $A P P \beta$, and a carboxyl-terminal fragment containing the $A \beta$ peptide. Cleavage of the carboxyl-terminal fragment by $\gamma$-secretase results in the formation of multiple $A \beta$ variants of 40-43 amino acids, which are prone to aggregate. The most abundant forms are 40 and 42 amino acids in length, $A \beta 40$ and $A \beta 42$. Both forms are capable of assembling into 60-100 diameter $\beta$-sheet fibrils that exhibit the characteristic cross- $\beta$ X-ray fiber diffraction pattern, and yield a redgreen birefringence when stained with Congo red [45]. The ratio of $A \beta 42$ to $A \beta 40$ is about 1:10. $A \beta 42$ plays a critical role in the pathogenesis of AD since its aggregative ability and neurotoxicity are much greater than those of $A \beta 40$. $A \beta 42$ oligomers initially formed as a seed accelerate the aggregation of $A \beta 40$ to form the amyloid plaques that eventually lead to the neurodegeneration (amyloid cascade hypothesis) [47].

\section{THE STRUCTURE OF AMYLOID IN ALZHEIMER DISEASE}

The formation of insoluble $A \beta$ deposits in the brain is a pathological hallmark of $\mathrm{AD}$. If the hypothesis that the neurotoxicity of $A \beta$ is mediated by amyloid fibril formation is correct, inhibition of $A \beta$ fibril formation might 
slow progression or prevent the disease. However, more recent studies have shown that fibrils are not the only neurotoxic structures and that $A \beta$ also assembles into soluble forms like small oligomers and protofibrils, which could be responsible for neurotoxicity [48]. A $\beta$ (1-40) and $A \beta(1-42)$ differ structurally by the absence or presence of two C-terminal amino acids [49]. The amino acid sequence of the $A \beta 1-42$ peptide is $D_{1} \mathrm{AEFRHDSG}_{9}$ YEVHHQKLVFFAED ${ }_{23}$ VGSNK $_{28}$ GAIIGLMVGGVV4 $0 \mathrm{I}_{42}$, where subscripts indicate residue numbers.

The solid state NMR data are consistent with an A $\beta 1-$ 40 monomer secondary structure composed of a structurally disordered $\mathrm{N}$-terminal region followed by two $\beta$ strand segments connected by a "loop" or "bend" segment. Structural model resulted by NMR data support a parallel $\beta$-sheet structure in fibrils formed by both the 40 and 42-residue $\beta$ amyloid peptides (A $\beta$ 1-40,42). Parallel $\beta$-sheets have been found by solid state NMR originally in fibrils formed by residues $10-35$ of $\beta$-amyloid (A $\beta$ 10-35) $[23,31,50]$. However, antiparallel $\beta$-sheets have also been found by solid state NMR in fibrils formed by shorter $\beta$-amyloid fragment. In agreement with the NMR experiment MD analysis of various structural models of short $\beta$-amyloid fragments, including parallel and antiparallel $\beta$-sheet structures suggested a strand-loop-strand structure with parallel $\beta$-sheets for A $\beta 10-35$ fibrils [51]. Recent solid state NMR and electron microscopy experiments have shown that $A \beta 1-40$ can form at least two distinct amyloid fibril structures, with distinct and self-propagating morphologies and molecular-level structural features, dependent on subtle variations in fibril growth conditions. Although all A $\beta 1-$ 40 fibril structures studied to date contain parallel $\beta$ sheets, distinct structures differ in the specific details of side-chain-side-chain contacts and in mass-per length (MPL) values [52].

Thin sections of amyloid fibrils formed from fragments of amyloid $\beta(A \beta)$, the amyloid fibril protein of Alzheimer's disease, show cross-sections containing five or six protofilaments $[23,53,54,55,56]$. The protofilaments were over $40 \AA$ in diameter and appeared as "beaded" structures with a $200 \AA$ periodicity $[53,54,57,58,59]$.

Electron microscopy studies have shown that amyloid fibrils consist of three to six protofilaments. It is possible that the exposed hydrophobic residues could be involved in helical packing among the protofilaments. It is known, for instance, that side-chain packing plays an important role in stabilizing helical coiled-coil bundles. While the center of pleated $\beta$-sheet structure is hydrophobic, the ends of the sheets are somewhat hydrophilic. Ionic interactions and/or hydrogen bond interactions as additional forces stabilizing the cross- $\beta$ structure have been proposed [60].

Oligomerization of $A \beta 42$ induced by the intermolecular $\beta$-sheet at positions $15-21$ and 24-32 would confine this radical species in the oligomer, making it possible to damage the cells continuously. However, this oligomer would not lead to the fibrils since the $\mathrm{C}$-terminal $\beta$-sheet is intramolecular (Figure 4(b)). As shown in Figure 4(a) and (b), the C-terminal residues in A $\beta 42$ play a critical role in its aggregative and neurotoxicity [61] and the intermolecular $\beta$-sheet in the C-terminal region of $A \beta 42$ seems to be preferable to long fibrils $[47,62]$. A $\beta(1-42)$ did not adopt a unique fold, but rather a mixture of rapidly interconverting conformations that were classified into three distinct families. The secondary structure analysis revealed that these conformations were dominated by loops and turns but that some helical structure formed in the C-terminal hydrophobic tail. Experimental studies of full-length $A \beta$ monomers in water (organic solvent mixtures) showed that the monomer structure consists of two $\alpha$-helical regions connected through an exible turn- or bend-like kink. The model of one helical turn of the twisted pleated $\beta$-sheet is composed of 48 monomers of $\mathrm{A} \beta$. Each monomer contains an antiparallel $\beta$-sheet. Overall, there are $96 \beta$-strands. Four strands form a unit and 24 units stack together along the fibril axis. If each unit were twisted by $15^{\circ}$ relative to its immediate neighbors (above and below) in the same way, 24 units would make a complete helical turn, with the
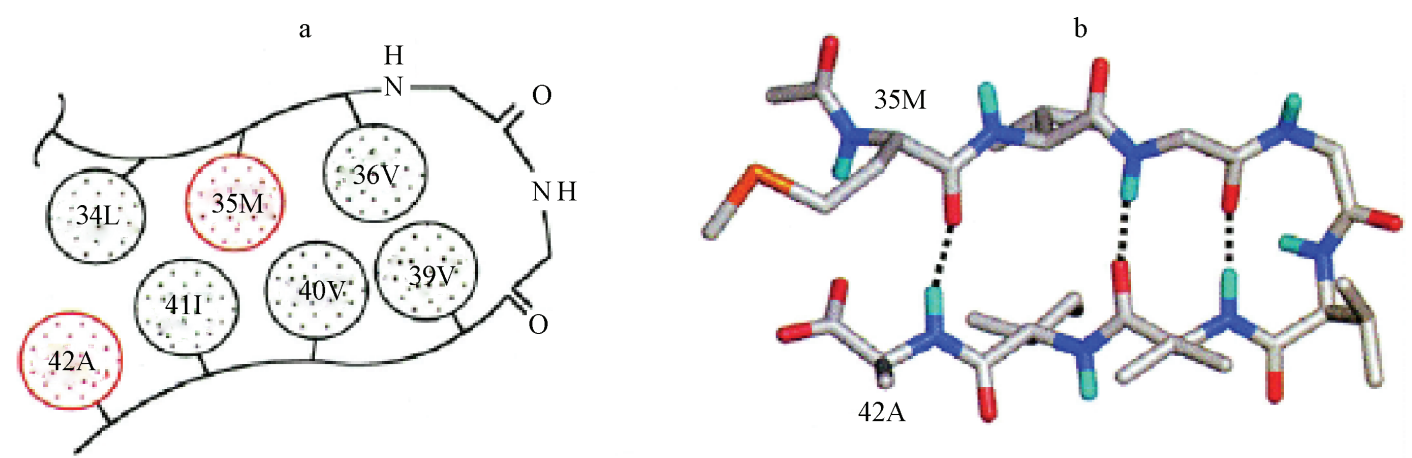

Figure 4. (a) A representation of the hydrophobic residue at the C-terminus of A $\beta 42$ [61]. (b) The intramolecular anti-parallel $\beta$-sheet at the C-terminus of $A \beta 42$ [112]. 
helical axis parallel to the fibril axis. Given that the angle between the two immediate strands from two different monomers was set at $15^{\circ}$, the helical twist formed by the 24 units in the model was actually nearly a complete turn $\left(\sim 350^{\circ}\right)$. Four strands in each unit layer are in an identical orientation, and those between two adjacent (above, below) unit layers are in an antiparallel arrangement (Figure 5(a) and (b)). In other words, the unit layers stack in an antiparallel fashion. The distances between the two adjacent strands in different unit layers and that between two strands within a unit layer are $\sim 4.7$ and $\sim 9.7 \AA$, respectively (Figure 5(c) and (d)). These distances are consistent with results from x-ray fibril diffraction studies on amyloid fibrils. NMR experiments on $\mathrm{A} \beta$ (10-35) monomer structure in an aqueous solution show a collapsed structure with loops, strands, and turns without any significant amount of $\alpha$-helical or $\beta$-strand content. These studies suggest that $\mathrm{A} \beta$ monomer structure is very sensitive to external conditions, such as temperature, $\mathrm{pH}$, and solvent. An $\mathrm{A} \beta$ (1-40) monomer structure considered with little $\alpha$-helix or $\beta$-strand at low temperatures. As the temperature was increased to physiological, substantial $\beta$-sheet content developed. A folded $A \beta$ (1-42) monomer, but not an $\mathrm{A} \beta$ (1-40) monomer, possesses a turn at G37-G38 stabilized by a hydrophobic interaction between V36 and V39 [63]. Preliminary cryo-electron microscopy of the amyloid fibrils formed from $A \beta(11-25)$ and from $A \beta$ (1-42) revealed that although they resembled one another closely in diameter and morphology, $A \beta$ (11-25) appeared to form more consistently homogeneous, straight, uniform fibrils with clearly definededges (Figure 6(a). The A $\beta$ (1-42) fibril showed less contrast, poorly defined edges and did not appear as straight or rigid (Figure 6(b). Close inspection of $A \beta$ (1-42) fibril images did not reveal any additional features (Figure 6(b). The $A \beta$ (1-42) fibrils showed the spacing between the bands measured 4.7-4.8 $\AA$, which corresponds to the hydrogen bonding distance between $\beta$-strands. These results appear to directly reveal the $\beta$-sheet structure a single amyloid fibril $[5,56]$. A model has been suggested for $A \beta$ amyloid protofilaments in which, $A \beta$ (12-42) folds into a $\beta$-hairpin and associates into four $\beta$-sheets, which twist around a central axis. In these models the $\beta$-strands are in register between the sheets. A $\beta$ (11-25) fibrils were more ordered, uniform structures. $A \beta$ (1-42) fibrils appeared to have less defined edges and this meant that selecting fibril images was more difficult. It is possible that this is because $A \beta$ (1-42) fibril structure is complicated by loops and disordered protein around the periphery of the fibrils whereas $\mathrm{A} \beta$ (11-25) fibrils constitute the core $\beta$-sheet structure. The $\beta$-strands clearly run perpendicular to the fibre axis. The strong, obvious striations visible across the fibre in these projections indicate that the $\beta$-sheets within the
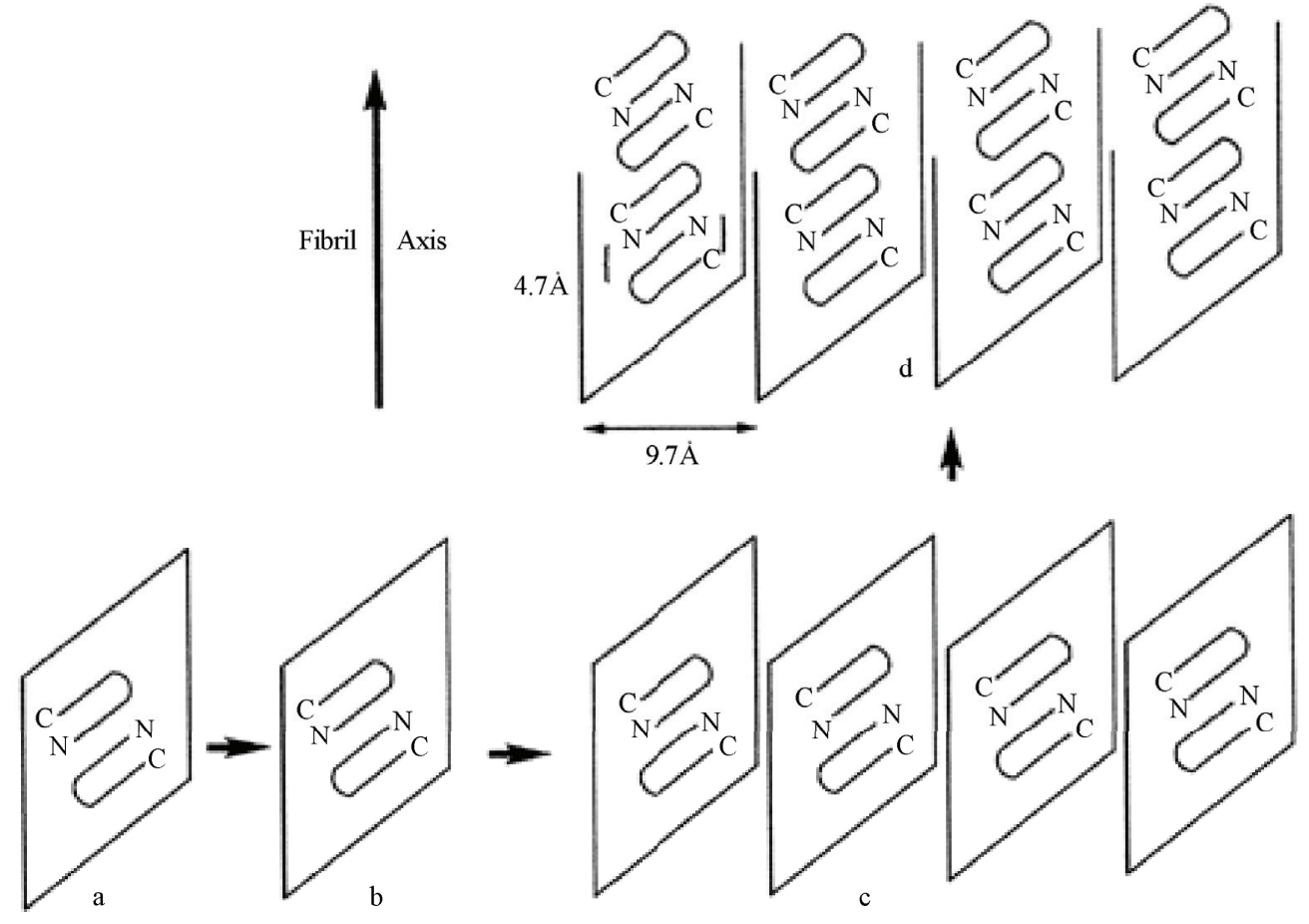

Figure 5. (a) A four-strand antiparallel $\beta$-sheet unit from the dimer interface. (b) A dimer of A $\beta$ 12-42 in an antiparallel $\beta$-sheet conformation. The distance between any two adjacent strands is $\sim 4.7 \AA$. (c) The dimer is translated three times in a direction perpendicular to the plane defined by the C $\alpha$ atoms of the dimer, each by $\sim 9.7 \AA$. An 8 -mer results. (d) A perfectly stacked 16-mer. It was constructed by stacking (parallel) two 8-mers together in the direction of the fibril axis [61]. 

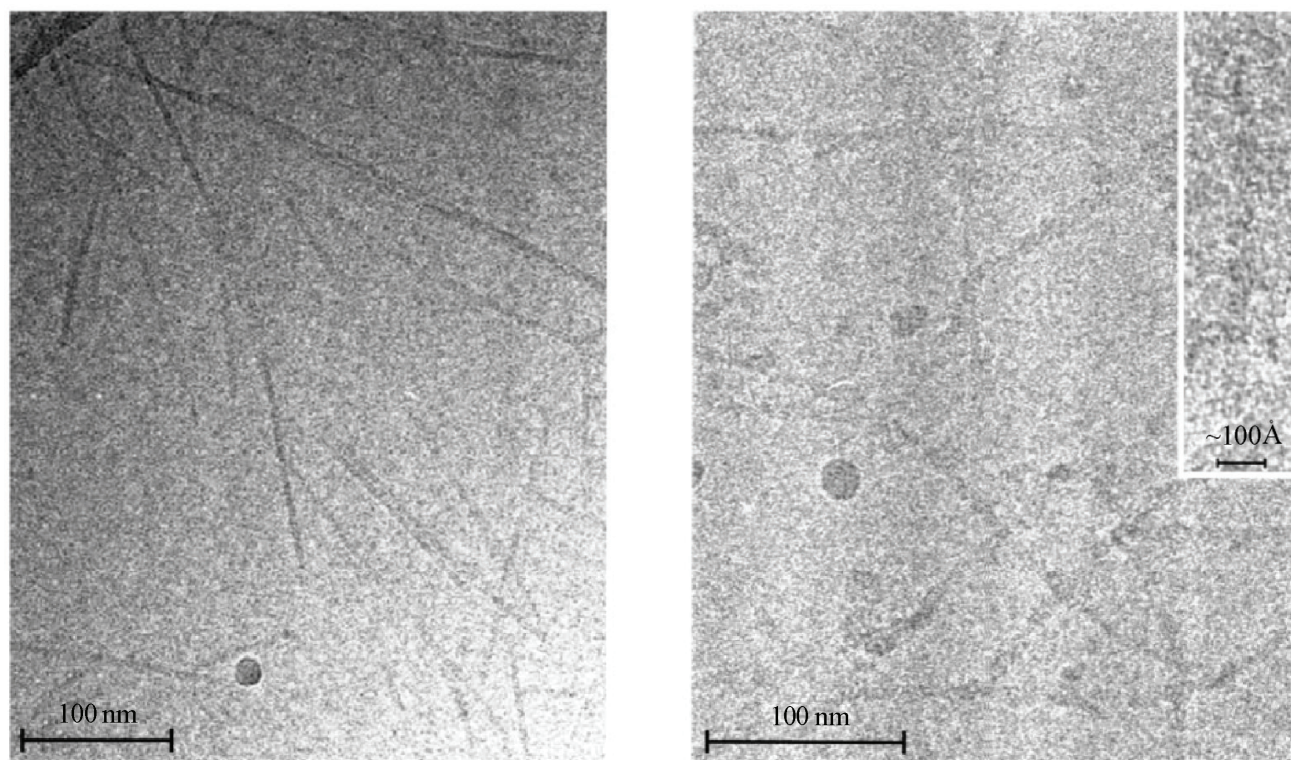

Figure 6. Low dose cryo electron micrograph of (a) $A \beta(11$ to 25 ) amyloid fibrils and (b) $A \beta(1$ to 42$)$ amyloid fibrils. The fibrils formed from both peptides are clearly long, straight and predominantly single. (b) A magnified view of $A \beta(1-42)$ fibril. It is clear from these images that the $A \beta(11$ to 25$)$ fibrils are straighter and more clearly defined than those of $A \beta(1$ to 42$)$ [5].

fibril are likely to be in exact register with one another, where a $\beta$-strand of one sheet is in register with the $\beta$-strand of the adjacent sheet, so that the strands reinforce one another in the image. Amyloid fibrils composed of $A \beta$ peptide are composed of continuous $\beta$-sheet structure where the $\beta$-strands run perpendicular to the fibre axis.

Electron microscopy has been used as a tool to examine the structure and morphology of these aggregates from ex vivo materials, but predominantly from synthetic amyloid fibrils assembled from proteins or peptides in vitro. Electron microscopy has shown that the fibrils are straight, unbranching, and are of a similar diameter (60$100 \mathrm{~A})$ irrespective of the precursor protein. Image processing has enhanced electron micrographs to show that amyloid fibrils appear to be composed of protofilaments wound around one another. In combination with other techniques, including X-ray fiber diffraction and solid state NMR, electron microscopy has revealed that the internal structure of the amyloid fibril is a ladder of $\beta$ sheet structure arranged in a cross- $\beta$ conformation [64]. The nonfibrillar oligomeric species are pathogenic, although reports differ as to whether soluble dimers or higher molecular weight protofibrils are toxic. The highly amyloidogenic $A \beta 42$ forms soluble oligomers extremely rapidly and $A \beta 42$ could form the pathogenic oligomeric species and/or amyloid fibrils and deposit in senile plaques faster than $A \beta 40[23,31,50,65]$.

Numerous evidence suggests that $\beta$-amyloid found abundantly in the brains of Alzheimer disease patients, is toxic in neuronal cell cultures through a mechanism in- volving free radicals. Therefore, anti-amyloid strategies are currently being investigated to lower the production of $A \beta$. Vitamin E prevents the oxidative damage induced by $\beta$-amyloid in cell culture and delays memory deficits [66], Another approach is using inhibitor investigation of anti-amyloid strategies to lower the production of $A \beta$. Using of chemical agents such as Congo red, rifampicin and benzofurans can prevent $A \beta$ oligomerization and the formation of neurotoxic protofibrils but are not appropriate in vivo due to their toxicity $[67,68]$.

\section{HUNTINGTON}

Huntington's disease (HD) is an autosomal-dominant neurodegenerative disorder caused by a CAG triplet repeat expansion coding for a poly-glutamine (polyQ) sequence in the N-terminal region of the Huntington (htt) protein [69]. The first symptoms of Huntington's disease usually occur in the third to fifth decade [70]. As the disease progresses, a variety of motor, emotional/ behavioral, and cognitive symptoms are experienced, including unsteadiness, trouble holding onto things, trouble walking, changes in sleeping patterns, delusions and hallucinations, intellectual decline, and memory loss Which Psychiatric symptoms are among the most common features [71,72].

CAG repeats resulting in long polyglutamine tracts have been implicated in the pathogenesis of at least eight neurodegenerative diseases including Huntington and several spinocerebellar ataxias [73]. Normally, Huntington is a cytoplasmic protein expressed at high levels in the striatal neurons vulnerable to degeneration in HD 
and at low or undetectable levels in the neurons resistant to degeneration. In HD brain, N-terminal fragments of mutant huntington were reported to accumulate and form inclusions in the nucleus and identified as a characteristic neuronal intracellular inclusion (NII) [74]. This inclusions contained $\beta$-pleated sheet stabilized by hydrogen bonds. In several cases, NI is spherical aggregates, sometimes assembled by insoluble amyloid-like fibrils. Aggregates outside the nucleus have also been observed, but it has been shown recently that nuclear localization is required for toxicity [75]. The poly-Q disorders are also associated with the formation of neuronal nuclear inclusions (NI) whose average size is about 5-7 $\mu \mathrm{m}$, and formed by aggregates of the protein with the expanded polyglutamine sequence $[75,76,77]$.

The hypothesis that amyloid structures are formed in Huntington's disease (HD) is supported by evidence that polyglutamine forms amyloid like protein aggregates in vitro, which stain with Congo Red (a histological stain for amyloid) and exhibit green birefringence under polarized light, [78,79]. Ultrastructural studies of brains of HD transgenic mice revealed neuronal intranuclear inclusion that contained aggregated huntingtin protein with granular or fibrillar morphology. Neuronal intranuclear inclusion with similar structural features also were detected in postmortem brains of HD and spinocerebellar ataxia type 3 patients as well as in stable and transiently transfected cell lines. Furthermore, recombinant proteins with an expanded poly(Q) stretch (51-122 glutamines) were found to form insoluble high molecular weight protein aggregates in vitro [80].

Increasing PG length correlates with the number of inclusions, which contributes to earlier onset of illness. In vivo inclusions occur primarily in subpopulations of neurons that are affected in the illnesses. In vitro expression of PG tracts has been shown to lead to aggregation of proteins by either cross linking or by polar-zipper hydrogen bonding $[81,82]$. Consistent with this, it was found that the rate of aggregate formation in vitro directly correlates with repeat length: the longer the poly $(\mathrm{Q})$ tract, the faster the aggregation rate. Similarly, the protein concentration required for aggregate formation decreased with an increase of the poly $(\mathrm{Q})$ repeat length. In vitro aggregation of $\mathrm{N}$-terminal, poly(Q)containing huntingtin peptides is self initiated and, like a crystallization or $A \beta$ formation, follows a nucleationdependent pathway. [83].

Thus the formation of amyloidlike huntingtin aggregates in vitro not only depends on poly(Q) repeat length but also critically depends on protein concentration and time [79]. Among these, formation of ordered huntingtin aggregates is highly poly(Q) repeat length-dependent, which correlated the age of onset and the severity of HD. The majority of adult-onset cases have expansions ranging from 41 to 55 units, whereas expansions of 70 and above invariably cause the juvenile form of the disease. Interestingly, pathological effects occur in patients only when the length of poly-Q exceeds a rather sharp threshold of $35 \pm 40$ glutamines. Thus length of the poly-Q tract correlates directly with the age of onset and with the severity of the symptoms in the diseases $[79,83]$.

Discovery of the gene underlying HD can be used as a genetic therapy for a logical step towards finding a cure. Animal models that closely mimic the neurobiological and clinical symptoms of the disease can be used to test experimental treatments for HD across different stages of the disease [71,84].

\section{PARKINSON}

Parkinson's disease (PD) is an age-related neurodegenerative disorder. In $80 \%$ cases $\mathrm{PD}$ is most common Parkinsonism which clinically is a syndrome characterized by tremor at rest, rigidity, slowness or absence of voluntary movement, postural, instability, and freezing. $\mathrm{PD}$ is a progressive disease, which affects both women and men. It has an effect on $\sim 1 \%$ of people beyond 65 years of age, with a higher prevalence in men [85-88]. The postmortem PD substantia nigra is characterized by sporadic intraneuronal cytoplasmic inclusions known as Lewy bodies (LB). The presence of Lewy bodies are associated with neurodegenerative disorders such as sporadic and familial Parkinson's disease (PD), dementia with LBs and the LB variant of Alzheimer's disease. The principal component of LBs is the protein $\alpha$-synuclein, but they also contain various amounts of other proteins, including the molecular chaperones, $\alpha \mathrm{B}$-crystallin, clusterin, torsin A, Hsp27 and Hsp70 [89,90,91,92,93].

$\alpha$-Synuclein protein and a fragment of it, called NAC. $\alpha$-Synuclein is a presynaptic protein, which was originally identified as the precursor protein for the non- $\beta$ amyloid component (NAC) of Alzheimer's disease (AD) senile plaques. NAC is a 35 amino acid peptide comprising amino acids $61-95$ of the $\alpha$-syn sequence and has been identified as the second major constituent in the plaques of AD brains $[94,95,96]$. The formation of NAC peptides in a crossed $\beta$-pleated sheet conformation was assessed by thioflavine-S staining. Only the aged samples of NAC(1-35) and NAC(1-18) were thioflavine-S positive, indicative of the presence of amyloid-like filaments $[97,98]$.

The involvement of $\alpha$-synuclein in neurodegenerative diseases was first suspected after the isolation of a $\alpha$ synuclein fragment (NAC) from amyloid plaques in Alzheimer's disease (AD). Later, two different $\alpha$-synuclein mutations were shown to be associated with autosomal-dominant Parkinson's disease (PD), but only in a small number of families. However, the discovery that $\alpha$-synuclein is a major component of Lewy bodies and Lewy neurites, the pathological hallmarks of PD, confirmed its role in PD pathogenesis [99]. 
Two autosomal dominant mutations in the $\alpha$-synuclein gene were linked to familial early onset PD: A53T and A30P. The mutations, A30P and A53T, do not affect the conformational behavior of the monomeric protein; wild-type $\alpha$-synuclein (WT), A53T, and A30P are all "natively unfolded" at low concentration. At higher concentrations, WT, A53T, and A30P all form amyloid fibrils of similar morphology by what appears to be a nucleation-dependent mechanism [97]. All three proteins also produce nonfibrillar oligomers that may be assembly intermediates, analogous to the $\mathrm{A} \beta$ protofibril. Fibrillization of $\alpha$-synuclein is clearly accelerated by the A53T mutation but the effect of the A30P mutation on fibril formation has not been determined, although A30P accelerates the formation of nonfibrillar oligomers and the disappearance of unsedimentable protein from solution $[100,101]$. Circular dichroism spectroscopy indicated that $\alpha$-synuclein undergoes a conformational change from random coil to $\beta$-sheet structure during assembly. X-ray diffraction and electron diffraction of the $\alpha$ synuclein assemblies showed a cross- $\beta$ conformation characteristicof amyloid [90].

In vitro multiple factors have been shown to accelerate $\alpha$-synuclein aggregation. In aqueous solution, $\alpha$ synuclein is natively unfolded within extended structure composed of random coil without a hydrophobic core. In vivo, it binds to rat brain vesicles via the first four 11mer N-terminal repeats. In vitro, it binds to monolayer phospholipid membranes, acquiring an $\alpha$-helical secondary structure probably formed by the seven N-terminal 11-residue repeats containing the conserved core sequence Lys-Thr-Lys-Glu-Gly-Val [102]. Therapeutic strategies aimed to prevent this aggregation are therefore envisaged. Although little has been learned about its normal function, $\alpha$-synuclein appears to interact with a variety of proteins and membrane phospholipids, and may therefore participate in a number of signaling pathways. In particular, it may play a role in regulating cell differentiation, synaptic plasticity, cell survival, and dopaminergic neurotransmission. Thus, pathological mechanisms based on disrupted normal function are also possible [102,103].

\section{SPONGIFORM AND FAMILIAL AMYLOIDOSIS DISEASES}

The transmissible spongiform encephalopathies (TSEs) or prion diseases form a group of fatal neurodegenerative diseases including bovine spongiform encephalopathy, Creutzfeldt-Jakob Disease (CJD) and GerstmannStra"ussler-Scheinker syndrome (GSS). TSEs, or prion diseases, are mammalian neurodegenerative disorders characterized by a posttranslational conversion and brain accumulation of an insoluble, protease-resistant isoform $\left(\mathrm{PrP}^{\mathrm{Sc}}\right)$ of the host-encoded cellular prion protein $\left(\mathrm{PrP}^{\mathrm{C}}\right)$ [104]. The diseases are rare, but outbreaks of acquired forms of CJD, such as variant CJD and iatrogenic CJD with cadaveric growth hormone or dura grafts, have prompted the development of therapeutic interventions and new diagnostic methods [105]. In humans, prion diseases result from infectious modes of transmission, Gerstmann-Sträussler-Scheinker Syndrome, Fatal Familial Insomnia; and modes of transmission. The clinical symptoms associated with each of the human prion disease forms vary dramatically [106,107].

Cellular prion protein, PrPC, is a predominantly $\alpha$ helical glycoprotein that remains attached to the outer membrane of the cells through a glycophosphatidyl inositol linkage. A $\beta$-sheet-rich conformational isoform of $\operatorname{PrP}^{\mathrm{C}}$, termed $\operatorname{PrP}^{\mathrm{SC}}$, has been considered to be the infectious agent of the fatal neurodegenerative diseases transmissible spongiform encephalopathies (TSE) and its hereditary forms of spongiform encephalopathies (SE). [104]. PrPS $^{C}$ exists as oligomers and amyloid polymers (fibres) and, unlike $\operatorname{PrP}^{\mathrm{C}}$, is resistant to digestion by proteinase $\mathrm{K}(\mathrm{PK})$, which is considered as an indicator of formation of $\mathrm{PrP}^{\mathrm{SC}}$. However, PrPC may undergo disease-associated structural modifications that do not lead to a protease-resistant molecule, indicating that prion disease can occur in the absence of $\mathrm{PrP}^{\mathrm{SC}}$; further protease-resistant prion protein forms without any infectivity can be generated. [108].

Familial amyloidosis may occur in patients with familial Mediterranean fever or it may arise from transthyretin mutations. Approximately 30 such mutations have been described [28]. Transthyretin, previously called prealbumin because it migrates ahead of albumin in standard electrophoretic separations, is a serum carrier of thyroid hormones and vitamin $A$. The mutant transthyretin is deposited as extracellular twisted $\beta$ pleated sheet fibrils in peripheral somatic and autonomic nerves and visceral organs; it causes autonomic and peripheral somatic disorders, and the disease is ultimately fatal [28]. Clinically, patients are susceptible to neuropathic, cardiopathic, or nephropathic complications. Type I familial hereditary generalized amyloidosis is inherited as an autosomal dominant gene mutation with a single amino acid substitution of methionine for valine at position 30 in transthyretin [28].

\section{CONCLUSIONS}

The topics discussed in this review provide a great deal of evidence for the proteins that have an intrinsic capacity of aggregating and forming structures such as amyloidfibrils. Aggregates are most commonly formed from the interaction of partially folded intermediates containing significant native-like structure. These interactions involve extended chain or $\beta$-sheet-like conformations. Thus, both ordered and disordered aggregates show increased $\beta$ structure relative to the native conformation (in the case of all- $\beta$ proteins, the increased $\beta$ structure is dis- 
tinct from that of the native protein).

Misfolded and aggregated species are likely to owe their toxicity to the exposure on their surfaces of regions of proteins that are buried in the interior of the structures of the correctly folded native states. The exposure of large patches of hydrophobic groups is likely to be particularly significant as such patches favour the interaction of the misfolded species with cell membranes $[109,110,111]$. Interactions of this type are likely to lead to the impairment of the function and integrity of the membranes involved, giving rise to a loss of regulation of the intracellular ion balance and redox status and eventually to cell death. The data reported so far strongly suggest that the conversion of normally soluble proteins into amyloid fibrils and the toxicity of small aggregates appearing during the early stages of the formation of the latter are common or generic features of polypeptide chains. Moreover, the molecular basis of this toxicity also appears to display common features between the different systems that have so far been studied.

Amyloidosis comprises a group of diseases in which protein tissue deposits have common morphologic structural, and staining properties but variable protein composition [28,37]. In this review we highlighted the relevance of amyloid fibril formation of different protein to diseases. The fibrillar morphology, diagnostic staining characteristics and underlying $\beta$-sheet structure of the proteins deposits led to them being classified as amyloid fibrils, and the diseases are now regarded as a protein misfolding disease. There are still many outstanding and critical questions regarding protein aggregation. Among these are questions about the detailed mechanism of the aggregation process, factors determining the kinetics of aggregation, the structural nature of the intermolecular interactions, and how aggregation may be effectively and efficiently prevented, especially in vivo.

\section{REFERENCES}

[1] Come, J. H., Fraser, P. E. and Lansbury, J., P. T., (1993) A kinetic model for amyloid formation in the prion diseases: Importance of seeding. P. Natl. Acad. Sci. USA. 90, 5959-5963.

[2] Chiti, F., Webster, P., Taddei, N., Clark, A., Stefani, M., Ramponi, G. and Dobson, C. M. (1999) Designing conditions for in vitro formation of amyloid protofilaments and fibrils. Biochemistry. 96, 3590-3594.

[3] Arrigo, P. A. and Muller, G. E. W. (2001) ((W. E. G. Muller (Managing Editor), P. J., I.Kostovic, Y. Kuchino, A. Macieira-coelho, R. E. Rhoads, Ed.). Ed.).

[4] van Montfort, L. R., Slingsby, C. and Vierling, E. (2002) Structure and function of the small heat shock protein/ $\alpha$ crystallin family of molecular chaperones. Protein. Chem. 59, 105-155.

[5] Serpell, C. L. a. (2000) Alzheimer's amyloid fibrils: Structure and assembly. Biochim. Biophys. Acta. 1502, 16-30.

[6] Pellarin, R. and Caflisch, A. (2006) Interpreting the ag- gregation kinetics of amyloid peptides. J. Mol. Biol 360, 882-892.

[7] Hall, D., Hirota, N. and Dobson, M. C. (2005) A toy model for predicting the rate of amyloid formation from unfolded protein. J. Mol. Biol. 195, 195-205.

[8] Dobson, M. C. (2001) The structure basis of protein folding and its links with human disease. Phil. Trans. R. Soc. Lond. B.. 356, 133-145.

[9] Dobson, M. C. (1999) Protein misfolding, evolution and disease. TIBS. 24, 329-332.

[10] Canet, D., Sunde, M., Last, A. M., Miranker, A., Spencer, A., Robinson, C. V. and Dobson, C. M. (1999) Mechanistic studies of the folding of human lysozyme and the origin of amyloidogenic behavior in its disease-related variants. Biochemistry. 38, 6419-27.

[11] MacPhee, E. C. and Dobson, C. M. (2000) Chemical dissection and reassembly of amyloid fibril formed by a peptide fragment of transthyretin. J. Mol. Biol. 297, 1203-1215.

[12] Shirahama, T. and Cohens, A. S. (1967) High-resolution electron microscopic. Analysis of the amyloid fibril. J. Cell. Biol.. 33, 679-708.

[13] Chamberlain, K. A., MacPhee, E. C., Zurdo, J., Morozova-Roche, A. L., Hill, A. H., Dobson, M. C. and Davis, J. J. (2000) Ultra structural organization of amyloid fibrils by atomic force microscopy. Biophys. J.. 79, 32823293.

[14] Conway, K. A. and Harper, J. D. (2000) Fibrils formed in vitro from $\alpha$-synuclein and two mutant forms linked to Parkinson's disease are typical amyloid. Biochemistry. 39, 2552-63.

[15] Cohen, A. S., Shirahama, T. and Skinner, M. (1982) Electron microscopy of amyloid. In electron microscopy of protein. Academic Press Inc, London UK. 3, 165-205.

[16] Jiménez, J. L., Guijarro, J. I., Orlova, E., Zurdo, J., Dobson, C. M., Sunde, M. and Saibil, H. R. (1999) Cryoelectron microscopy structure of an SH3 amyloid fibril and model of the molecular packing. EMBO. 18, 815821.

[17] Serpell, L. C., Sunde, M., E., F. P., Luther, P. K., Morris, E. P., Sangren, O., Lundgren, E. and Blake, C. C. (1995) Examination of the structure of the transthyretin amyloid fibril by image reconstruction from electron micrographs. J. Mol. Biol.. 254, 113-8.

[18] Kirschner, A. D., Abraham, C. and Selkoe, J. D. (1986) $\mathrm{X}$-ray diffraction from intraneuronal paired helical filaments and extraneuronal amyloid fibers in alzheimer disease indicates cross- $\beta$ conformation. P. Natl. Acad. Sci. USA. 83, 503-508.

[19] Blake, C. and Serpell, L. (1996) Synchrotron X-ray studies suggest that the core of the transthyretin amyloid fibril is a continuous $\beta$-sheet helix. Structure. 4, 989-98.

[20] Sunde, M., Serpell, L. C., Bartlam, M., Fraser, P. E., Pepys, M. B. and Blake, C. F. (1997) Common core structure of amyloid fibrils by synchrotron X-ray diffraction. J. Mol. Biol. 273, 729-739.

[21] Guijarro, I. L., Sunde, M., Jones, A. J., Campbell, D. I. and Dobson, M. C. (1998) Amyloid fibril formation by an SH3 domain. Biochemistry. 95, 4224-4228.

[22] Plakoutsi, G., Bemporad, F., Calamai, M., Taddei, N., Dobson, M. C. and Chiti, F. (2005) Evidence for a mechanism of amyloid formation involving molecular 
reorganisation within native-like precursor aggregates. J. Mol. Biol. 351, 910-922.

[23] Cecchini, M., Curcio, R., Pappalardo, M., Melki, R. and Caflisch, A. (2006) A Molecular Dynamics Approach to the Structural Characterization of Amyloid Aggregation. J. Mol. Biol. 357, 1306-1321.

[24] Hatters, D. M., Wilson, M. R., Easterbrook-Smith, S. B. and Howlett, G.J. (2002) Suppression of apolipoprotein C-II amyloid formation by the extracellular chaperone, clusterin Eur. J. Biochem. 269, 2789-2794.

[25] Haley, D. A., Horwitz, J. and Stewart, P. L. (1998) The small Heat-Shock protein,aB-crystallin, has a variable quaternary structure. J. Mol. Biol. 277, 27-35.

[26] Jacchieri, G. S. (1998) Study of a-helix to b-strand to bsheet transitions in amyloid: the role of segregated hydrophobic b-strands. Biophysical Chemistry. 74, 23-34.

[27] Milner-White, J. E., Watson, D. J., Qi, G. and Hayward, S. (2006) Amyloid formation may involve a- to b-sheet interconversion via peptide plane flipping. Structure. 14, 1369-1376.

[28] Horwitz, S., Thomas, C., Gruener, G., Nand, S. and Shea, F. J. (1998) MR of Leptomeningeal Spinal and Posterior Fossa Amyloid. AJNR Am J Neuroradiol. 19, 900-902.

[29] Horowitz, S., Thomas, C., Gruener, G., Nand, S. and Shea, F. J. (1998) MR of Leptomeningeal Spinal and Posterior Fossa Amyloid. AJNR Am J Neuroradiol. 19, 900-902.

[30] Tycko, R. (2000) Solid-state NMR as a probe of amyloid fibril structure. Curr. Opin. Chem. Biol. 4, 500-506.

[31] Makin, S. O., Atkins, E., Sikorski, P., Johansson, J. and Serpell, C. L. (2005) Molecular basis for amyloid fibril formation and stability. PNAS. 102, 315-320.

[32] Otoo, N. H., Lee, G.K., Qiu, W. and Lipke, N. P. (2008) Candida albicans Als adhesins have conserved amyloidforming sequences. Eukaryotic Cell. 7, 776-782.

[33] Religa, D., Laudon, H., Styczynska, M., Winblad, B., Näslund, J. and Haroutunian, V. (2003) Amyloid $\beta$ Pathology in Alzheimer's Disease and Schizophrenia. Am J Psychiatry. 160, 867-872.

[34] Barrel, J. M., Broadley, S. A., Schaffar, G. and Hart, F. U. (2004) Role of molecular chaperones in protein misfolding diseases. Semin. Cell. Dev. Biol. 15, 17-29.

[35] Ellidson and Bottomley (2004) The role of Misfolding in the pathogenesis of human diseases. IUBMB life. 56(3), 119-123.

[36] Carrell, R. W. and Lomas, D. A. (1997) Conformational diseas. Lancet. 350, 134-138.

[37] Small, W. G., Kepe, V., Ercoli, M. L., Siddarth, P., Bookheimer, Y. S., Miller, J. K., Lavretsky, H., Burggren, C. A., Cole, M. G., Vinters, V. H., Thompson, M. P., Huang, C. S., Satyamurthy, N., Phelps, E. M. and Barrio, R. J. (2006) PET of brain amyloid and Tau in mild cognitive impairment. N. Engl. J. Med. 355, 2652-2663.

[38] Selkoe (2003) Folding proteins in fatal ways. Nature. 426(6968), 900-904.

[39] Han, H., Weinreb, H. P. and Lansbury, T. P. (1995) The core Alzheimer's peptide NAC forms amyloid fibrils which seed and are seeded by p-amyloid: is NAC a common trigger or target in neurodegenerative disease? Chemistry \& Biology. 2, 163-169.

[40] Shoghi-Jadid, K., Barrio, R. J., Kepe, V., Wu, M. H., Small, W. G., Phelps, E. M. and Huang, C. S. (2005) Im- aging b-amyloid fibrils in Alzheimer's disease: a critical analysis through simulation of amyloid fibril polymerization. Nuclear Medicine and Biology. 32, 337-351.

[41] Miura, Y., You, C. and Ohnishi, R. (2008) Inhibition of Alzheimer amyloid aggregation by polyvalent trehalose. SCIENCE AND TECHNOLOGY OF ADVANCEDMATERIALS (Sci. Technol. Adv. Mater). 9, 1-6.

[42] Sefton, F. C. and Yu, G. (2008) Ab Predictor of Alzheimer disease symptoms Arch Neurol. 65, 875-876.

[43] Malm, T., Ort, M., Tä htivaara, L., Jukarainen, N., Goldsteins, G., Puolivä li, J., Nurmi, A., Pussinen, R., Ahtoniemi, T., Miettinen, K. T., Kanninen, K., Leskinen, S., Vartiainen, N., Yrjä nheikki, J., Laatikainen, R., HarrisWhite, E. M., Koistinaho, M., Frautschy, A. S., Bures, J. and Koistinaho, J. (2006) b-Amyloid infusion results in delayed and age-dependent learning deficits without role of inflammation or b-amyloid deposits. PNAS 103, 8852-8857.

[44] Grundman, M., Petersen, R. C., Ferris, H. S., Thomas, R. G., Aisen, S. P., Bennett, A. D., Foster, L. N., Jack, R. C., Galasko, R. D., Doody, R., Kaye, J., Sano, M., Mohs, R., Gauthier, S., Kim, T. H., Jin, S., Schultz, N. A., Schafer, K., Mulnard, R., Dyck, V. H. C., Mintzer, J., Zamrini, Y. E., Cahn-Weiner, D. and Thal, J. L. (2004) Mild cognitiveimpairment can be distinguished from Alzheimer Disease and normal aging for clinical trials. Arch Neurol. 61, 59-66.

[45] Huang, J. H. T., Yang, S. D., Plaskos, N. P., Go, S., Yip, M. C., Fraser, E. P. and Chakrabartty, A. (2000) Structural Studies of Soluble Oligomers of the Alzheimer bAmyloid Peptide. J. Mol. Biol. 297, 73-87.

[46] Rosenberg, N. R. (2000) Explaining the cause of the amyloid burden in Alzheimer disease. Arch Neurol. 59, 1367-1368.

[47] Irie, K., Murakami, K., Masuda, Y., Morimoto, A., Ohigashi, H., Ohashi, R., Takegoshi, K., Nagao, M., Shimizu, T. and Shirasawa, T. (2005) Structure of B-amyloid fibrils and its relevance to their neurotoxicity: implications for the pathogenesis of Alzheimer's disease. Journal of Bioscience and Bioengineering. 99, 437-447.

[48] Rivière, C., Richard, T., Quentin, L., Krisa, S., Mérillon, M. J. and Monti, P. J. (2007) Inhibitory activity of stilbenes on Alzheimer's b-amyloid fibrils in vitro. Bioorganic \& Medicinal Chemistry. 15, 1160-1167.

[49] Hardy, J. and Selkoe, D. J. (2002) The amyloid hypothesis of Alzheimer's disease: Progress and problems on the road to therapeutics. Science. 297, 353-356.

[50] Sachse, C., Xu, C., Wieligmann, K., Diekmann, S., Grigorieff, N. and Fändrich, M. (2006). Quaternary structure of a mature amyloid fibril from Alzheimer's $A \beta(1-40)$ peptide. J. Mol. Biol. 362, 347-354.

[51] Ma, B. Y. and Nussinov, R. (2002) Stabilities and conformations of Alzheimer's b-amyloid peptide oligomers (Ab (16-22), Ab (16-35) and Ab (10-35)): Sequence effects. Proc. Natl Acad. Sci. USA. 99, 14126-14131.

[52] Buchete, V. N., Tycko, R. and Hummer, G. (2005) Molecular dynamics simulations of Alzheimer's b-Amyloid protofilaments. J. Mol. Biol. 353, 804-821.

[53] JimeÂnez, L. J., Tennent, G., Pepys, M. and Saibil, R. H. (2001) Structural Diversity of ex vivo Amyloid Fibrils Studied by Cryo-electron Microscopy. J. Mol. Biol. 311, 241-247. 
[54] Gilead, S. and Gazit, E. (2005) Self-organization of short peptide fragments: From amyloid fibrils to nanoscale supramolecular assemblies. Supramolecular Chemistry. 17, 87-92.

[55] Pellarin, R., Guarnera, E. and Caflisch, A. (2007) Pathways and intermediates of amyloid fibril formation. J. Mol. Biol. 374, 917-924.

[56] Serpell, L. C. and Smith, J. M. (2000) Direct visualisation of the b-sheet structure of synthetic Alzheimer's amyloid. J. Mol. Biol. 299, 225-231.

[57] Klement, K., Wieligmann, K., Meinhardt, J., Hortschansky, P., Richter, W. and Fändrich, M. (2007) Effect of different salt ions on the propensity of aggregation and on the structure of Alzheimer's $A \beta(1-40)$ amyloid fibrils. J. Mol. Biol. 373, 1321-1333.

[58] Ban, T., Hoshino, M., Takahashi, T., Hamada, D., Hasegawa, K., Naiki, H. and Goto, Y. (2004) Direct observation of $\mathrm{Ab}$ amyloid fibril growth and inhibition. J. Mol. Biol. 344, 757-767.

[59] Idicula-Thomas, S. and Balaji, V. P. (2007) Protein aggregation: A perspective from amyloid and inclusionbody formation. CURRENT SCIENCE. 92, 758-767.

[60] Li, L., Darden, A. T., Bartolotti, L., Kominos, D. and Pedersen, G. L. (1999) An atomic model for the pleated $\mathrm{b}$-sheet structure of Ab-amyloid protofilaments. Biophys J. 76, 2871-2878.

[61] Weinreb, P. H., Jarrett, J. T. and Lansbury, P. T. (1994) Peptide models of a hydrophobic cluster at the Cterminus of the amyloid protein. J. Am. Chem. Soc. 116, 10835-10836.

[62] Williams, A. D., Portelius, E., Kheterpal, I., Guo, J., Cook, K. D., Xu, Y. and Wetzel, R. (2004) Mapping Aamyloid fibril secondary structure using scanning proline mutagenesis. J. Mol. Biol. 335, 833-842.

[63] Lazo, N. D. and Downing, D. T. (1999). Fibril formation by amyloid b-proteins may involve b-helical protofibrils. J. Pept. Res., 53, 633-640.

[64] Thusnelda, S. and Louise C, S. (2005) Structure and morphology of the Alzheimer's amyloid fibril, Microscopy Research and Technique, 67, 210-217.

[65] El-Agnaf, A. M. O., Mahil, S. D., Patel, P. B. and Austen, M. B. (2000) Oligomerization and Toxicity of bAmyloid-42 Implicated in Alzheimer's Disease. Biochemical and Biophysical Research Communications. 273, 1003-1007.

[66] Grundman, M. (2000) Vitamin E and Alzheimer disease: the basis for additional clinical trials. Am Clin Nutr. 71, 630S-636S.

[67] Tuszynski, H. M., Thal, L., Pay, M., Salmon, P. D., Sang U, H., Bakay, R., Patel, P., Blesch, A., Vahlsing, L. H., Ho, G., Tong, G., Potkin, G. S., Fallon, J., Hansen, L., Mufson, J. L., Kordower, H. J., Gall, C. and Conner, J. (2005) A phase 1 clinical trial of nerve growth factor gene therapy for Alzheimer disease. Nat. Med. 11, 551555.

[68] Martin, K. B., Meinert, L. C. and Breitner, S. C. J. (2002) Double placebo design in a prevention trial for Alzheimer's disease. Cont. Clin. Trials. 23, 93-99.

[69] Di'az-Hernández, M., Torres-Peraza, J., SalvatoriAbarca, A., Morán, M.A., Gómez-Ramos, P., Alberch, J. and Lucas, J. J. (2005) Full motor recovery despite striatal neuron loss and formation of irreversible amyloidlike inclusions in a conditional mouse model of Huntington's Disease. The Journal of Neuroscience. 25(42), 9773-9781.

[70] Gusella, J. F., Wexler, N. S., Conneally, P. M., Naylor, S. L., Anderson, M. A., Tanzi, R. E., Watkins, P. C., Ottina, K., Wallace, M. R., Sakaguchi, A. Y., Young, A. B., Shoulson, I., Bonilla, E. and Martin, J. B. (1983) A polymorphic DNA marker genetically linked to Huntington; s disease. Nature. 306, 234-238.

[71] Anderson, K. E., Louis, E. D., Stern, Y. and Marder, K. S. (2001) Cognitive Correlates of Obsessive and Compulsive Symptoms in Huntington's Disease. Am J Psychiatry. 158, 799-801.

[72] Mitchell, I. J., Heims, H., Neville, E.A. and Rickards, H. (2005) Huntington's disease patients show impaired perception of disgust in the gustatory and olfactory modalities. J. Neuropsychiatry Clin Neurosci. 17, 119-121.

[73] Hirakura, Y., Azimov, R., Azimova, R. and Kagan, L. B. (2000) Polyglutamine-Induced Ion Channels: A Possible Mechanism for the Neurotoxicity of Huntington and Other CAG Repeat Diseases. Journal of Neuroscience Research. 60, 490-494.

[74] Davies, W. S., Beardsall, K., Turmaine, M., DiFiglia, M., Aronin, N. and Bates, P. G. (1998) Are neuronal intranuclear inclusions the common neuropathology of tripletrepeat disorders with polyglutamine-repeat expansions? THE LANCET. 351, 131-33.

[75] Temussi, A. P., Masino, L. and Pastore, A. (2003) From Alzheimer to Huntington: why is a structural understanding so difficult? The EMBO Journal. 22, 355-361.

[76] Karpug, V. M., Becher, W. M., Springer, E. J., Chabas, D., Youssef, S., Pedotti, R., Mitchell, D. and Steinman, L. (2002). Prolonged survival and decreased abnormal movements in transgenic model of Huntington disease, with administration of the transglutaminase inhibitor cystamine. Nat. Med. 8, 143-149.

[77] Karpuj, V. M., Becher, W. M., Springer, E. J., Chabas, D., Youssef, S., Pedotti, R., Mitchell, D. and Steinman, L. (2002) Prolonged survival and decreased abnormal movements in transgenic model of Huntington disease, with administration of the transglutaminase inhibitor cystamine. Nature Medicine. 8, 143-149.

[78] Hoffner, G. and Djian, P. (2000) Protein aggregation in Huntington's disease. Biochimie. 84, 273-278.

[79] Mcgowan, P. D., Vanroon-Mom, W., Holloway, H., Bates, P. G., Mangiarini, L., Cooper, S. J. G., R., F. L. and Snell, G. R. (2000) Amyloid-lioke inclusions in huntington, s disease. Neuroscience. 100, 677-680.

[80] Gutekunst, A. C., Li, H. S., Yi, H., Mulroy, S. J., Kuemmerle, S., Jones, R., Rye, D., Ferrante, J. R., Hersch, M.S. and Li, J.X. (1999) Nuclear and Neuropil Aggregates in Huntington's Disease: Relationship to Neuropathology. The Journal of Neuroscience. 19(7), 2522-2534.

[81] Ross, A. C. (2002) Polyglutamine pathogenesis: emergence of unifying mechanisms for Huntington's disease and related disorders. Neuron. 35, 819-822.

[82] Dahlgren, R. P., Karymov, A. M., Bankston, J., Holden, T., Thumfort, P., Ingram, V. M. and Lyubchenko, L. Y. (2005) Atomic force microscopy analysis of the Hunting- 
ton protein nanofibril formation. Nanomedicine: Nanotechnology, Biology and Medicine. 1, 52-57.

[83] Scherzinger, E., Sittler, A., Schweiger, K., Heiser, V., Lurz, R., Hasenbank, R., Bates, P.G., Lehrach, H. and Wanker, E. E. (1999) Self-assembly of polyglutaminecontaining huntingtin fragment into amyloid-like fibrils: Implications for Huntington's disease pathology. Proc. Natl. Acad. Sci. USA. 96, 4604-4609.

[84] Borlongan, C. V., Koutouzis, T. K., Freeman, T. B., Cahill, D. W. and Sanberg, P. R. (1995) Behavioral pathology induced by repeated systemic injections of 3nitropropionic acid mimics the motoric symptoms of Huntington's disease. Brain Res. 697, 254-257.

[85] Spillantini, G. M., Crowther, A. R., Jakes, R., Hasegawa, M. and Goedertm, M. (1998) A-synuclein in filamentous inclusions of Lewy bodies from Parkinson's disease and dementia with Lewy bodies. Proc. Natl. Acad. Sci. USA. 95, 6469-6473.

[86] Recchia, A., Debetto, P., Negro, A., Guidolin, D., Skaper, D. S. and Giusti, P. (2004) A-Synuclein and Parkinson's disease. The FASEB J. 18, 617-626.

[87] Dauer, W. and Przedborski, S. (2003) Parkinson's disease: mechanisms and models. Neuron. 39, 889-909.

[88] Hariz, G. and Hriz, I. M. (2000) Gender distribution in surgery for Parkinson's disease. Parkinsonism Relate Disord. 6, 155-157.

[89] Iwaki, T., Wisniewski, T., Iwaki, A., Corbin, E., Tomokane, N., Tateishi, J. and Goldman, J. E. (1992) Accumulation of aB-crystallin in central nervous system glia and neurons in pathologic conditions. Am. J. Path. 140, 345356.

[90] Serpell, C. L., Berriman, J., Jakes, R., Goedert, M. and Crowther, A. R. (2000) Fiber diffraction of synthetic asynuclein filaments shows amyloid-like cross-b conformation. PNAS. 97, 4897-4902.

[91] Mizutani, T., Inose, T., Nakajima, S., Kakimi, S., Uchigata, M. and Ikeda, K. (1998) Familial parkinsonism and dementia with ballooned neurons, argyrophilic neuronal inclusions, atypical neurofibrillary tangles, tau-negative strocytic fibrillary tangles, and Lewy bodies.. Acta Neuropathol. (Berl). 95, 15-27.

[92] Sasaki, K., Doh-ura, K., Wakisaka, Y. and Iwaki, T. (2002) Clusterin/apolipoprotein J is associated with cortical Lewy bodies: immunohistochemical study in cases with alpha-synucleinopathies. Acta Neuropathol. (Berl). 104, 225-230.

[93] McLean, P. J., Kawamata, H., Shariff, S., Hewett, J., Sharma, N. and Ueda, K. (2002) Torsin A and heat shock proteins act as molecular chaperones: suppression of alpha-synuclein aggregation. J. Neuro. 83, 846-854.

[94] Splllantini, G. M. a., Crowther, A. R., JAKES, R., Cairns, J. N., Lantos, L. P. and Goedert, M. (1998) Filamentous a-synuclein inclusions link multiple system atrophy with Parkinson's disease and dementia with Lewy bodies. Neuroscience. 251, 205-208.

[95] El-Agnaf, A. M. O., Jakes, R., Curran, D. M. and Wallace, A. (1998) Eiects of the mutations Ala30 to Pro and Ala53 to Thr on the physical and morphological properties of K-synuclein protein implicated in Parkinson's disease. FEBS. 440, 67-70.
[96] Spillantini, G. M. a., Crowther, A. R., JAKES, R., Cairns, J. N., Lantos, L. P. and Goedert, M. (1998) Filamentous a-synuclein inclusions link multiple system atrophy with Parkinson's disease and dementia with Lewy bodies. Neuroscience. 251, 205-208.

[97] El-Agnaf, A. M. O., JAKES, R., Curran, D. M., Middleton, D., Ingenito, R., Bianchi, E., Pessi, A., Neill, D. and Wallace, A. (1998) Aggregates from mutant and wildtype a-synuclein proteins and NAC peptide induce apoptotic cell death in human neuroblastoma cells by formation of L-sheet and amyloid-like claments. FEBS. 440, $71-75$.

[98] Arima, K., Hirai, S., Sunohara, N., Aoto, K., Izumiyama, Y., Ue'da, K., Ikeda, K. and Kawai, M. (1999) Cellular co-localization of phosphorylated tau- and NACPr asynuclein-epitopes in Lewy bodies in sporadic Parkinson's disease and in dementia with Lewy bodies. Brain Research. 843, 53-61.

[99] Arima, K., Ue'da, K., Sunohara, N., Hirai, S., Izumiyama, Y., Tonozuka-Uehara, H. and Kawai, M. (1998) Immunoelectron-microscopic demonstration of NACPrasynuclein-epitopes on the filamentous component of Lewy bodies in Parkinson's disease and in dementia with Lewy bodies. Brain Research. 808, 93-100.

[100] Conway, A. K., Lee, J. S., Rochet, C. J., Ding, T. T., Williamson, E. R. and Lansbury, T. P. (2000) Acceleration of oligomerization, not fibrillization, is a shared property of both a-synuclein mutations linked to early-onset Parkinson's disease: Implications for pathogenesis and therapy. PNAS. 97, 571-576.

[101] Conway, A. K., Harper, J. D. and Lansbury, P. T. (2000) Fibrils Formed in Vitro from R-Synuclein and Two Mutant Forms Linked to Parkinson's Disease are Typical Amyloid. Biochem. 39, 2552-2563.

[102] Lu"cking, B. C. and Brice, A. (2000) a-synuclein and Parkinson's disease. CMLS, Cell. Mol. Life Sci. 57, 1894-1908.

[103] Williams, A. D., Portelius, E., Kheterpal, I., Guo, J., Cook, K. D., Xu, Y. and Wetzel, R. (2004) Mapping A amyloid fibril secondary structure using scanning proline mutagenesis. J. Mol. Biol. 335, 833-842.

[104] Casalone, C., Zanusso, G., Acutis, P., Ferrari, S., Capucci, L., Tagliavini, F., Monaco, S. and Caramelli, M. (2004) Identification of a second bovine amyloidotic spongiform encephalopathy: Molecular similarities with sporadic Creutzfeldt-Jakob disease. PNAS 101, 3065-3070.

[105] Ishikawa, K., Doh-ura, K., Kudo, Y., Nishida, N., Murakami-Kubo, I., Ando, Y., Sawada, T. and Iwaki, T. (2004) Amyloid imaging probes are useful for detection of prion plaques and treatment of transmissible spongiform encephalopathies. Journal of General. 85, 1785-1790.

[106] Aguzzi, A., Heikenwalder, M. and Miele, G. (2004) Progress and problems in the biology, diagnostics, and therapeutics of prion diseases. J. Clin. Invest. 114, 153160.

[107] Weissmann, C. and Aguzzi, A. (2005) Approaches to therapy of prion diseases. Ann. Rev. of Med. 56, 321344.

[108] Nandi, P. K. and Nicole, J.-C. (2004) Nucleic acid and prion protein interaction produces spherical amyloids which can function in vivo as coats of spongiform en- 
cephalopathy agent. J. Mol. Biol. 344, 827-837.

[109] Kourie, J I and A, S. A. (2000) Properties of cytotoxic peptide-induced ion channels. Am J Physiol Cell Physiol. 278, C1063-C1087.

[110] Kourie, J. I. and L, H. C. (2002) Ion channel formation and membrane-linked pathologies of misfolded hydrophobic proteins:the role of dangerous unchaperoned molecules. Clin Exp Pharmacol Physiol, 29, 741-753.

[111] Volles, M. J. and T, L. P. (2001) Vesicle permeabilization by protofibrillar $\alpha$-synuclein: comparison of wild-type with Parkinson's disease linked mutants and insights in the mechanisms. Biochem. 40, 7812.7819.
[112] Williams, A. D., Portelius, E., Kheterpal, I., Guo, J., Cook, K. D., Xu, Y. and Wetzel, R. (2004) Mapping A amyloid fibril secondary structure using scanning proline mutagenesis. J. Mol. Biol. 335, 833-842.

[113] Dobson. (2004) Principle of protein folding, Misfolding and aggregation. Semin. Cell. Dev. Biol. 15, 3-16.

[114] Thomas, Q. and Pederson. (1995) Defective protein folding as a basis of human diseases. TIBS. 20 (11), 456459.

[115] Welch and Brown (1996) Influence of molecular and chemical chaperones on protein folding. Cell Stress Chaperone. 1(2), 109-115.

\section{Appendix}

$\begin{array}{ll}\text { APP } & \text { Abbreviation: Amyloid precursor protein } \\ \text { AD } & \text { Alzheimer's disease } \\ \text { HD } & \text { Huntington's disease } \\ \text { PD } & \text { Parkinson's disease } \\ \text { LBs } & \text { Lewy bodies } \\ \text { TSEs } & \text { Transmissible spongiform encephalopathies }\end{array}$

